\title{
ABERRANT BEATS OF WOLFF-PARKINSON-WHITE CONFIGURATION IN ARTERIOSCLEROTIC HEART DISEASE
}

\author{
BY
}

\author{
IRWIN HOFFMAN, MILTON H. MORRIS, LOUIS FRIEDFELD, AND ROBERT
} D. GITTLER

\begin{abstract}
From the Department of Medicine, Beth Israel Hospital, New York City, and the Cardiac Clinic, St. Joseph's Hospital, Far Rockaway, New York

Received April 13, 1955
\end{abstract}

Evidence has been presented by Prinzmetal et al. (1952) and Borduas et al. (1955) that electrocardiographic beats characterized by short P-R and long QRS intervals may occur in the absence of an accessory pathway by-passing the A-V node. In animal experiments, Prinzmetal observed beats of WPW type after repeated electrical stimulation of the A-V node, and noted in these same animals the spontaneous occurrence of various supraventricular tachycardias. Several arteriosclerotic patients studied by Prinzmetal demonstrated similar electrocardiographic phenomena, and at necropsy were found to have fibrotic disease of the A-V node and no accessory conduction system. These clinical and experimental observations indicate that WPW beats may occur on an acquired basis, secondary to nodal disease.

In other experiments, Prinzmetal induced beats of WPW type in dogs after repeated ventricular stimulation with the A-V node intact. These observations harmonize with those of Kossman et al. (1950) who recorded such beats during cardiac catheterization when the catheter was in direct contact with the endocardial surface. Similar complexes have been observed by Prinzmetal during the course of acute myocardial infarction, frequently in association with ventricular premature beats and ventricular arrhythmias.

On the basis of his extensive studies, including high-speed cinematographic techniques, Prinzmetal has deduced that accelerated conduction through part of the A-V node is responsible for aberrant complexes. He believes this to be true both in instances of nodal disease (" nodal" accelerated conduction) and ventricular irritability ("ventricular" accelerated conduction). In this latter type, the accelerated conduction through the A-V node may be on a reflex basis.

Five instances of WPW aberration have been seen during the past two years in patients with arteriosclerotic heart disease. Of these, four are considered to be of acquired type, and only one an example of classical, congenital, Wolff-Parkinson-White syndrome (1954).

\section{CASE REPORTS}

Case 1. A 54-year-old man, who had had effort angina for one year, was admitted because of severe chest pain, of 48 hours' duration. The clinical course and serial electrocardiograms were characteristic of posterior wall infarction.

Fig. 1A demonstrates numerous premature ventricular beats. In Fig. 1B, in addition, beats of WPW type may be seen in leads II, AVR, and V6. Fig. 1C shows a run of ventricular tachycardia (Lead I).

On three separate occasions, the oral administration of procaine amide or quinidine abolished the premature ventricular beats, the beats of WPW type, and the short runs of ventricular tachycardia.

This case represents the "ventricular" type of acquired WPW aberration. In the experience of Prinzmetal (1952) "ventricular" WPW is usually associated with anterior infarction, and " nodal" WPW with posterior infarcts. Perhaps with increasing experience additional examples 
A
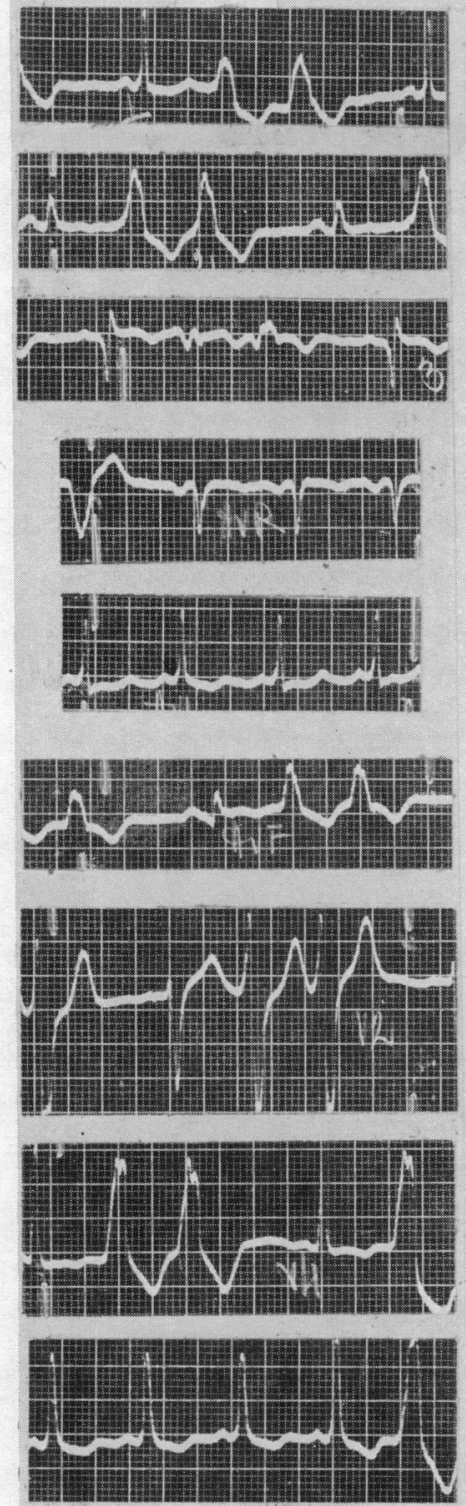

V 6

I

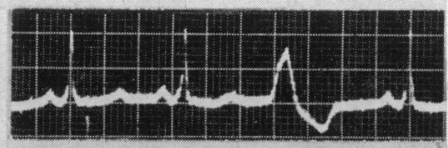

II

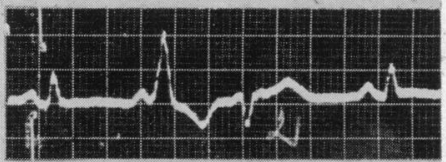

III

AVR

AVL

AVF
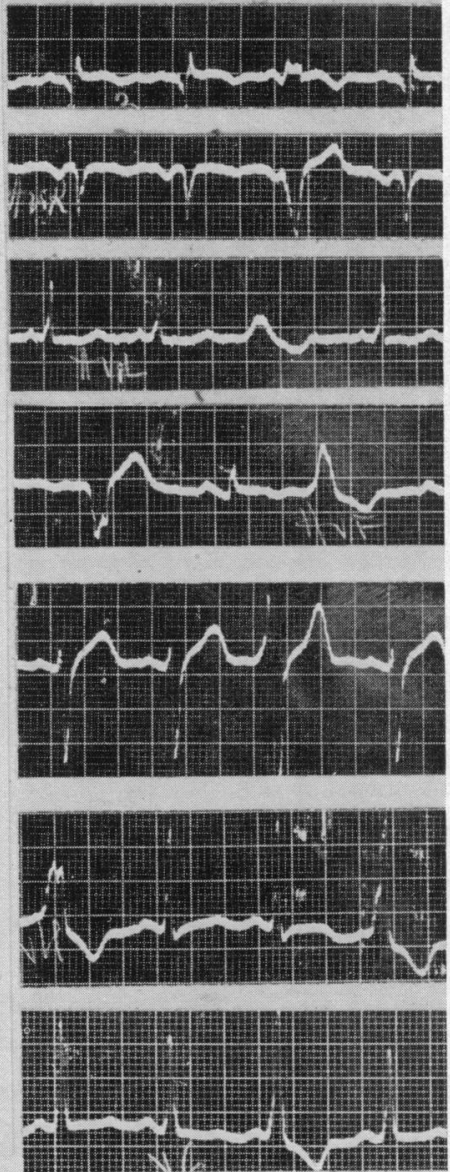

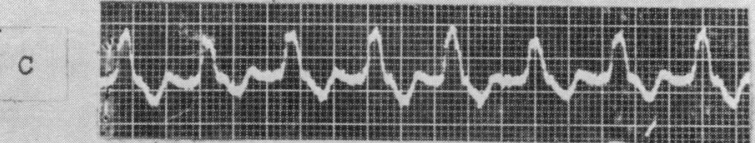

FIG. 1.-Electrocardiograms in Case 1. (A) Posterior infarction and premature ventricular beats. (B) Complexes of WPW type in leads II, AVR, and V6. (C) Ventricular tachycardia. 
of the " ventricular" type in posterior infarcts will be seen. There can be no doubt of the efficacy of procaine amide and quinidine in suppressing not only the arrhythmia and premature ventricular beats, but the aberrant conduction as well.

Case 2. A hyperterssive woman aged 52 was admitted because of dyspnœa and substernal pressure, both on effort. For three days she had noted paroxysmal nocturnal wheezing and orthopnœa. Previous blood pressures had averaged 190/120. The blood pressure on admission was $140 / 90$; at the apex gallop rhythm and friction rub were audible. Basal moist râles were present. Treatment included oxygen, morphine, digitalis, and heparin. The course was favourable, with gradual recovery over a four-week period.

Fig. 2A and 2B show serial $\mathrm{T}$ changes as well as prominent $\mathrm{Q}$ in lead III. Localization of the infarct was not certain, but acute anterior disease and old posterior disease seemed likely. On one occasion only, WPW beats were seen alternating with normal beats. This is shown in Fig. 2C.

Case 3. A 58-year-old man was admitted because of progressive effort angina. The diagnosis of coronary insufficiency had been made four months before admission. His need for nitroglycerine had increased from three or four daily to almost hourly. X-ray studies demonstrated left ventricular enlargement. Physical examination, white counts, and sedimentation rates remained normal during three weeks in hospital.

The electrocardiograms (Fig. 3A and 3B) show serial S-T and T changes, as well as $Q$ waves in leads $I$ and AVL. Anterolateral disease was considered definite, but actual acute infarction could not be diagnosed with certainty. Lead I of Fig. 3B shows beats of WPW type alternating with normally conducted beats.

Comment on Cases 2 and 3. These two cases demonstrate beats of WPW type alternating with normal beats. Because of the absence of premature ventricular complexes, the aberrant conduction is probably of the "nodal" variety. No arrhythmia occurred in either patient. Quinidine or procaine amide were not given to prevent possible arrhythmia, as at the time these patients were treated the full significance of the aberrant beats was not appreciated. Similar patients observed now would in all likelihood be given a nodal depressant drug as prophylaxis against arrhythmia.

Case 4. A 62-year-old man entered the clinic because of fatigue, dyspnœa, and intermittent claudication. Pertinent findings included a blood pressure of 190/80, a regular bradycardia of 50 beats a minute, and sclerotic retinal and brachial vessels. Posterior tibial and dorsalis pedis pulses were absent. A loud, long apical systolic murmur was audible. X-rays showed that the heart was not enlarged.

The electrocardiogram (Fig. 4) shows in the frontal plane leads, a normal sinus rhythm, short $\mathrm{P}-\mathrm{R}$ and wide QRS intervals. A spontaneous change in mechanism then occurred, as the praecordial leads reveal a 2-1 A-V block, with each conducted beat having the WPW configuration.

The coexistence of A-V block and WPW aberration accords well with Prinzmetal's view that a diseased A-V node may at times conduct more slowly than normal, and at other times more rapidly. He has observed two such cases which ultimately came to autopsy; fibrotic nodal disease was found in each case. Levine and Burge (1948) reported a very similar case. Their patient had acute myocardial infarction with complete heart block. Occasional atrial impulses were conducted, however, and all of these were characterized by short P-R and wide QRS complexes of the WPW type. Autopsy disclosed an accessory right lateral bundle, which apparently became functional after destruction of the A-V node by disease. Thus, when WPW aberration and heart block co-exist, accessory conduction tissue as well as accelerated nodal conduction must be considered.

Case 5. A 30-year-old man was in hospital because of severe crushing substernal pain of one hour's duration. The pain radiated to the neck and was accompanied by severe dyspnœa. The past history included repeated, frequent bouts of palpitation. A cardiac study at the age of 16 had disclosed Wolff-Parkinson-White syndrome. The present hospital course was favourable, with discharge in three weeks. Serial studies of white count and sedimentation rate were equivocal.

Fig. $5 \mathrm{~A}$ is the electrocardiogram taken at the age of 16 and showing short $\mathrm{P}-\mathrm{R}$ and wide $\mathrm{QRS}$ intervals. Fig. 5B, taken on admission, is not significantly different. In Fig. 5C, however, a spontaneous reversion to normal conduction occurs in many beats, disclosing markedly abnormal T waves in leads II, III, and V6. 


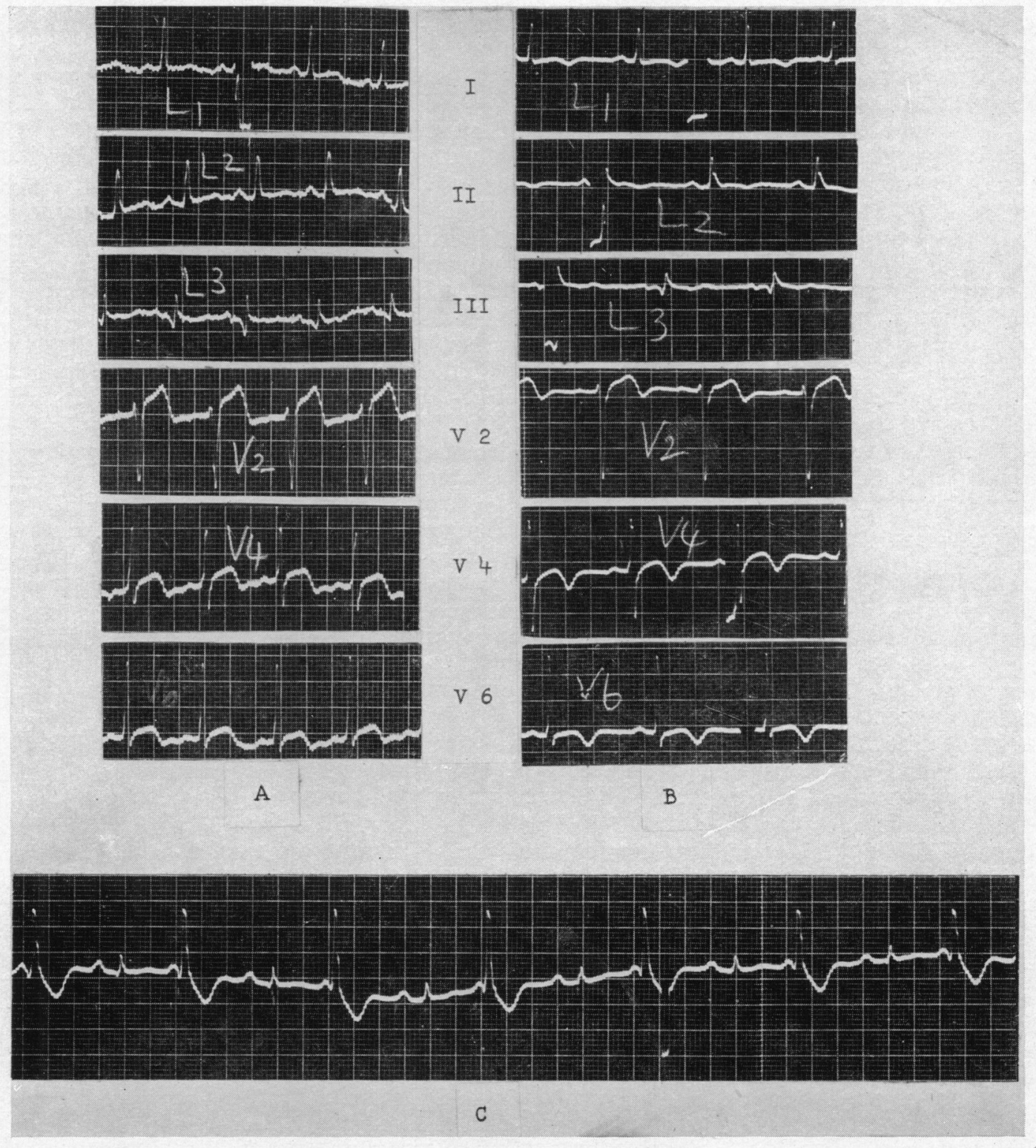

FiG. 2.-Electrocardiograms in Case 2. (A) and (B) Serial S-T and T changes. (C) Beats of WPW type alternating with normally conducted beats. 


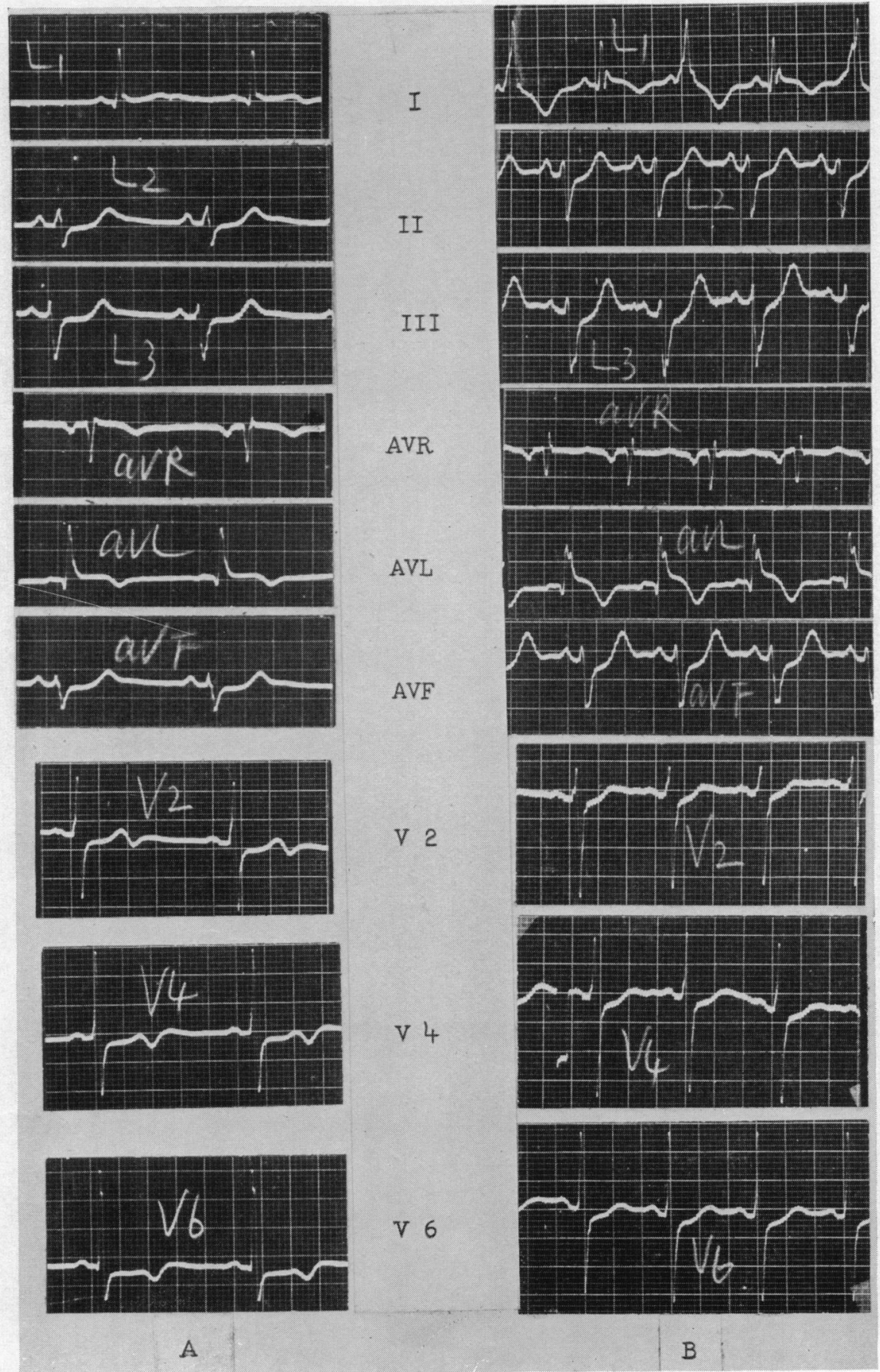

Fig. 3.-Electrocardiograms in Case 3. Serial S-T and T changes. Alternating beats of WPW type in lead I (B). 


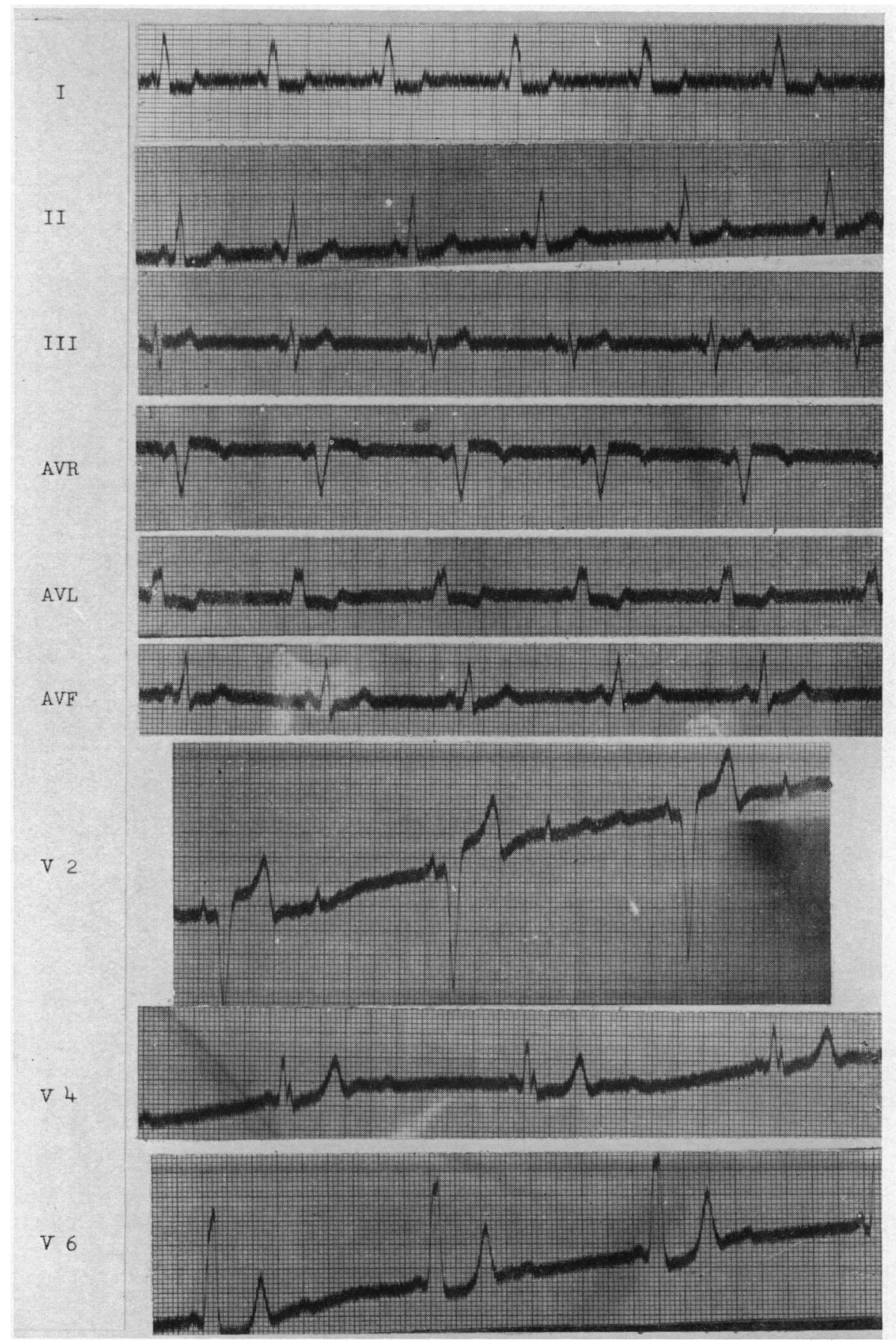

FIG. 4.-Electrocardiogram in Case 4. Frontal plane leads show WPW aberration. V2, V4, V6 show in addition 2:1 atrioventricular block. 


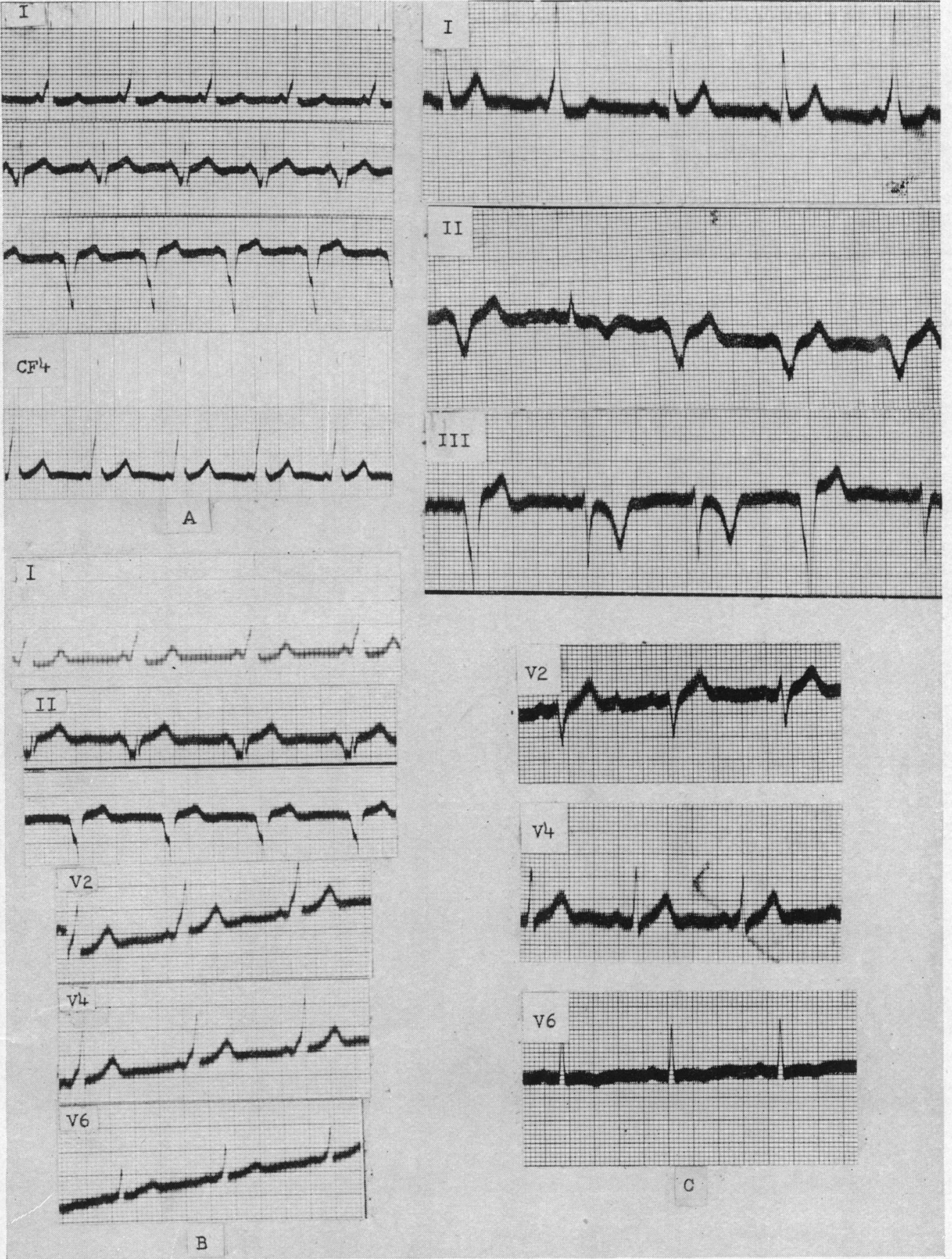

FIG. 5.-Electrocardiograms in Case 5. (A) Electrocardiogram at age 16, showing WPW aberration. (B) Electrocardiogram on admission at age 30 for chest pain. (C) Abnormal T waves in leads II, III, and V6 recorded with spontaneous reversion to normal conduction. 
This case illustrates coronary insufficiency and perhaps myocardial infarction in a young man with classic WPW syndrome. In this instance, as in the cases of Zoll and Sacks (1945) and Goldbloom and Dumanis (1946), the aberrant conduction obscured the diagnosis.

\section{DisCUSSION}

These five instances of WPW aberration in the course of arteriosclerotic heart disease were seen during a two-year period at three active hospitals. The incidence, therefore, may be considered low. The proportion between acquired (4 cases) and congenital (1 case) varieties is, nevertheless, striking.

The recognition of these complexes is important as they may precede serious arrhythmiassupraventricular in the "nodal "type and ventricular in the "ventricular" type. In the present series quinidine and procaine amide were used in one case, with good effect. Even though these aberrant beats are not always followed by arrhythmia, it would seem reasonable to administer nodal depressant drugs as a prophylactic measure if no contra-indication, such as heart block, exists.

\section{SUMMARY}

Five examples of electrocardiographic aberration of WPW type occurring in the course of arteriosclerotic heart disease are presented.

Of the five, four are considered to be acquired and one congenital.

These aberrani beats may precede arrhythmias, and, therefore, suggest the use of prophylactic nodal depressant drugs.

The authors wish to thank Col. Ryle A. Radke, Chief, Medical Service, Tokyo Army Hospital, for permission to include Cases 2 and 3, and Dr. Orgain of Duke Hospital for the electrocardiograms in Case 5.

\section{REFERENCES}

Borduas, J. L., Rakita, L., Kennamer, R., and Prinzmetal, M. (1955). Circulation, 11, 69.

Goldbloom, A. A., and Dumanis, A. A. (1946). Ann. intern. Med., 25, 362.

Kossman, C. E., Berger, A. R., Briller, S. A., Rader, B., and Brumlik, J. (1950). Circulation, 1, 902.

Levine, H. D., and Burge, J. C. (1948). Amer. Heart J., 36, 431.

Prinzmetal, M., Kennamer, R., Corday, E., Osborne, J. A., Fields, J., and Smith, L. A. (1952). Accelerated Conduction. Grune and Stratton, New York.

-. Personal communication.

Wolff, L. (1954). Circulation, 10, 282.

Zoll, P. M., and Sacks, D. R. (1945). Amer. Heart J., 30, 527. 